\title{
In vitro gastrointestinal digestion of microencapsulated extracts of Flourensia cernua, F. microphylla, and F. retinophylla
}

\author{
D. Jasso de Rodríguez ${ }^{\mathrm{a}, *}$, G.N. Puente-Romero ${ }^{\mathrm{a}}$, L. Díaz-Jiménez ${ }^{\mathrm{b}}$, R. Rodríguez-García ${ }^{\mathrm{a}}$, \\ Z.A. Genisheva ${ }^{\mathrm{d}}$ \\ ${ }^{a}$ Universidad Autónoma Agraria Antonio Narro, 25315 Saltillo, Coahuila, Mexico \\ ${ }^{\mathrm{b}}$ SRNyE, Cinvestav-Saltillo, 25900 Ramos Arizpe, Coahuila, Mexico \\ ${ }^{\mathrm{c}}$ Biocampo S.A. de C.V., Blvd. Dr. Jesús Valdés Sánchez Km. 10, Fracc. Presa de las Casas, 25350 Arteaga, Coahuila, Mexico \\ ${ }^{\mathrm{d}}$ Centre of Biological Engineering, Universidade do Minho, Campus de Gualtar, 4710-057 Braga, Portugal
} H. Ramírez-Rodríguez ${ }^{a}$, J.A. Villarreal-Quintanilla ${ }^{a}$, M.L. Flores-López ${ }^{c}$, D.A. Carrillo-Lomelía,

\section{A R T I C L E I N F O}

\section{Keywords:}

Microcapsules

Gastrointestinal digestion

Controlled release

F. cernua

F. microphylla

F. retinophylla.

\begin{abstract}
A B S T R A C T
Recently, some species of the genus Flourensia have been identified by their potential health effects (e.g. antiinflammatory and apoptotic). Encapsulation of plant extracts is a process that can allow an adequate dosage administration, as well as to protect bioactive compounds and improve their controlled release in the gastrointestinal (GI) system. Therefore, the aims of this work were: to microencapsulate the ethanol extracts of $F$. cernua, F. microphylla, and F. retinophylla; and to evaluate the controlled release of the microencapsuled extracts in an in vitro GI system. Leaves of Flourensia spp. were collected in wild sites of Coahuila State, and the ethanol extracts were obtained by the Soxhlet method. The encapsulation was performed by the gelation technique, using alginate. The microcapsules formed were characterized in terms of total phenol content (Folin-Ciocalteu method), antioxidant activity by the 2,2-diphenyl-1-picrylhydrazyl (DPPH), 2,2'-azino-bis (3-ethylbenzthiazoline-6-sulphonic) diammonium acid (ABTS), and the ferric reducing antioxidant power (FRAP) assays, scanning electron microscopy (SEM), and thermal analysis, and in vitro GI digestion. The microcapsules were found to have spherical-shape and a micro-scale dimension in the range of $2.1-68.8 \mu \mathrm{m}$. Also, the built of microcapsules was confirmed by the appearance of an exothermic peak centered at $200{ }^{\circ} \mathrm{C}$ in the DSC analysis. F. microphylla noted for its strong antioxidant activity, even in its encapsulated form. In the gastric system the extracts of fresh microcapsules were released from $7.7 \%$ to $14.5 \%$, while values of $26.5 \%$ to $53.3 \%$ were observed for those dried. For the intestinal system, the higher release was observed for dried microcapsules (59.9\% to $78.4 \%$ ) than for those fresh (26.3\% to $30.2 \%)$. Thus, it was demonstrated that the alginate microcapsule protected the extracts until they were delivered to the target site in the GI model, and this effect was better with the dried microcapsules of Flourensia spp. This study would set the guide for the application of Flourensia spp. extracts in order to take advantage of their benefits to human health.
\end{abstract}

\section{Introduction}

Flourensia spp. are wild plants that occur on a vast area from the south of USA crossing Mexico, Peru, Bolivia up to Argentina (Dillon, 1984). The genus Flourensia is formed by about 42 species, which at least nine of them have been found in Mexico (Rios, 2015), and three are considered as endemic of the state of Coahuila: F. cernua, F. microphylla, and F. retinophylla (Jasso de Rodríguez et al., 2007). F. cernua, commonly known as "hojasén" is the most studied species, as it has proven antifungal, antibacterial, and antioxidant properties (Jasso de
Rodríguez et al., 2017b; Mendez et al., 2012; Castillo et al., 2010; Salazar et al., 2008; Molina-Salinas et al., 2006). The presence of terpenes such as eudesmol, limonene, and borneol has been reported in its chemical composition (Vines, 1960), as well as alkaloid traces (Téllez et al., 2001). Other phytochemicals of diverse nature have been found for ethanol extracts of leaves of $F$. cernua, such as oxygenated sesquiterpenes, sesquiterpenes, pyrazines, and steroids (Jasso de Rodríguez et al., 2017b). Also, F. retinophylla (locally known as "yerba de mula") has antifungal activity against phytopathogenic fungi; which is characterized by the presence of amides, flavonols, and flavanones within

\footnotetext{
* Corresponding author.

E-mail address: dianajassocantu@yahoo.com.mx (D.J. de Rodríguez).
} 
its structure (Jasso de Rodríguez et al., 2017b; Stuppner and Müller, 1994; Dillon and Marby, 1977). Meanwhile, F. microphylla has shown antifungal, and also anti-inflammatory, and apoptotic effects on HT-29 colon cancer cells; in which were identified polyols, fatty acids esters, phenolic amines, phenolic compounds, and flavonoids (Jasso de Rodríguez et al., 2017b,a).

The rich composition of these species represents an outstanding source of bioactive agents to be used in the treatment of inflammatory processes affecting humans. However, their application depends on the chemical stability and bioavailability of the phytochemicals (Fang and Bhandari, 2010). Such is the case of polyphenols, which, due to their chemical nature are easily degradable by the action of light, heat, and pH, among other factors (Cilek et al., 2012; Munin and Edwards-Lévy, 2011). Also, flavonoids are highly sensitive to oxidant environments, $\mathrm{pH}$, and temperature (McClements and Xiao, 2017). Additionally, most of the phytochemicals of interest present in some extracts, have a low solubility in water which limits their application (Pinheiro et al., 2017). This is the case of the extracts of the Flourensia spp. Microencapsulation of plant extracts is a good alternative to overcome this problem, which gives stability to the phytochemicals present in their composition (Gupta, et al., 2016; Fabra et al., 2016). Microencapsulation is defined as a technology of micro-scale $(1.0-5000 \mu \mathrm{m})$ packaging of bioactive materials (solid, liquid or gaseous) in a polymeric matrix, being able to release these materials under controlled conditions (Hu et al., 2019; Cerqueira et al., 2014; Fang and Bhandari, 2010). This technology is widely used in food and pharmaceutical industries, and is constantly improving to develop encapsulation materials, as well as release mechanisms of the active ingredients (Cerqueira et al., 2014; Desai and Park, 2005). The study of the release of bioactive compounds from capsules in the gastrointestinal (GI) tract receives special interest, in such a way that it is possible to guarantee their integrity on their path to the release in a specific site and achieve the maximum effects (Jafari and McClements, 2017). In order to predict the release mechanisms of the bioactive compounds from microcapsules are used kinetic models of zero-order $\left(K_{\mathrm{o}}\right)$, first-order $\left(K_{1}\right)$, and Higuchi $\left(K_{H}\right)$ (Safdar et al., 2019). These models may optimize the extract release during the passage in the GI tract.

There is a constant interest in the study of the properties of plants of the Mexican semi-desert, and considering the potential of the bioactive compounds present in the species of Flourensia mentioned above, the aims of this work were: (1) to microencapsulate the ethanol extracts of F. cernua, F. microphylla, and F. retinophylla; and (2) to evaluate the controlled release of the microencapsuled extracts in an in vitro gastrointestinal system.

\section{Materials and methods}

\subsection{Plant collection}

Samples of F. cernua, F. microphylla, and $F$. retinophylla were randomly collected in a semi-arid zone south of the state of Coahuila, Mexico. The samples were placed in plastic bags and taken to the Phytochemistry Laboratory of the Universidad Autónoma Agraria Antonio Narro (UAAAN). Then, the leaves were separated from the branches, and dried at $60^{\circ} \mathrm{C}$ for $48 \mathrm{~h}$ (Mapsa, Mexico). Subsequently, the leaves were ground in a Thomas Wiley mill (Swedesboro, NJ, USA) using a $2 \mathrm{~mm}$ mesh. The ground material was stored in polyethylene bags until further analyses.

\subsection{Ethanol extracts of Flourensia spp.}

The extracts were obtained by the Soxhlet method as described Jasso de Rodríguez et al. (2017b). Briefly, $14 \mathrm{~g}$ of a sample of dried and ground leaves were placed in a Whatman no. 1 filter paper inside a Soxhlet extractor and refluxed with $200 \mathrm{~mL}$ of ethanol for $72 \mathrm{~h}$. After the extraction process, the solvent was separated by rotary evaporation
(Büchi Laboratoriums-Technik, Switzerland). Finally, the extract was subjected to drying in an oven at $50{ }^{\circ} \mathrm{C}$ for $24 \mathrm{~h}$ to eliminate the remaining solvent. The obtained extracts were weighed and stored in amber bottles and kept in desiccator at $25{ }^{\circ} \mathrm{C}$ and $0 \%$ of relative humidity $(\mathrm{RH})$ until further tests.

\subsection{Microencapsulation of Flourensia spp. extracts}

The microencapsulation of extracts was carried out as previously reported by Calero et al. (2008) with some modifications. Firstly, $3 \mathrm{~g}$ of sodium alginate were dissolved in $100 \mathrm{~mL}$ of distilled water and adjusted to $200 \mathrm{~mL}$; then, $500 \mathrm{mg}$ of Flourensia spp. extract was added (Solution A). This procedure was carried out for each Flourensia extract. The mixture was constantly stirring until complete dissolution. Then, $3 \mathrm{~g}$ of calcium chloride were added to $200 \mathrm{~mL}$ of distilled water (Solution B). Solution A was placed in a separatory funnel and dropped into the Solution $B$ for the formation of the microcapsules under continuously stirred at $600 \mathrm{rpm}$. The obtained capsules were separated into two batches, one of which was subjected to drying at room temperature ( $d=$ dried microcapsules) and the second was kept in suspension ( $f=$ fresh microcapsules) until further analyses.

In order to clarify, the concentration of the extracts used in the encapsulation process was selected according to preliminary tests (data not shown).

\subsection{Extracts and microencapsulated extracts characterization}

\subsubsection{Total Phenolic Content (TPC)}

The content of total phenols was determined by the Folin-Ciocalteu (FC) method described by Singleton et al. (1999), adapted to microplate. For all analyzes, $5 \mu \mathrm{L}$ of sample (i.e. extracts or microencapsulated extracts) were placed in a 96-well microplate. Then, $60 \mu \mathrm{L}$ of the FC reagent, $15 \mu \mathrm{L}$ of $\mathrm{Na}_{2} \mathrm{CO}_{3}$ solution $(7.5 \%$, w/v), and $200 \mu \mathrm{L}$ of distilled water were added to each well. The reaction was incubated at $60{ }^{\circ} \mathrm{C}$ for $5 \mathrm{~min}$. Immediately, the absorbance was measured in a UV/Vis spectrophotometer (Synergy HT, BioTek Instruments, Inc. USA) at $700 \mathrm{~nm}$. A calibration curve of gallic acid was prepared $(0.2,0.4,0.6$, 0.8 , and $\left.1.0 \mathrm{mg} \mathrm{L}^{-1}, R^{2}=0.9919\right)$. The TPC was expressed as milligrams equivalents of gallic acid per $100 \mathrm{mg}$ of sample (mg GAE $100 \mathrm{mg}^{-1}$ extract). Experiments were carried out in triplicate.

\subsubsection{Antioxidant activity by DPPH assay}

The quantification of the capacity of free radical capture of the extracts and microencapsulated extracts, was determined by measuring the degree of discoloration caused by the components of the sample to a methanol solution of 2,2-diphenyl-1-picrylhydrazyl (DPPH), according to Ballesteros et al. (2015) with slight modifications. The reaction was carried out in a 96-well microplate, placing in each well $25 \mu \mathrm{L}$ of sample and $200 \mu \mathrm{L}$ of DPPH solution $(150 \mu \mathrm{M}$, dissolved in methanol to an absorbance value from $0.70 \pm 0.01$ to $515 \mathrm{~nm}$ ), and incubating at room temperature in the dark for $1 \mathrm{~h}$. Then, the absorbance was measured in a microplate spectrophotometric reader (Synergy HT, BioTek Instruments, Inc., USA) at $515 \mathrm{~nm}$. Methanol was used as control. The antioxidant activity was expressed as percentage of DPPH-scavenging activity relative to the control using the following equation:

$\%$ Inhibición $=\left(1-\frac{A_{s}}{A_{0}}\right) \times 100$

where $A_{0}$ and $A_{s}$ are the absorbance of the control solution and the absorbance of the sample solution, respectively. All experiments were performed in triplicate.

\subsubsection{Antioxidant activity by FRAP assay}

The antioxidant capacity of the samples by the ferric reducing antioxidant power (FRAP) was carried out according to the method of 
Benzie and Strain (1996). Briefly, a FRAP solution of $10 \mathrm{mM}$ 2,4,6-tri(2pyridyl)-s-triazine (TPTZ) in $40 \mathrm{mM} \mathrm{HCl}, 20 \mathrm{mM}$ ferric chloride hexahydrate solution, and $300 \mathrm{mM}$ buffer acetate (3.1 g sodium acetate trihydrate and $16 \mathrm{~mL}$ glacial acetic acid, $\mathrm{pH}$ 3.6) in a ratio 1:1:10, was mixed and incubated $10 \mathrm{~min}$ at $37^{\circ} \mathrm{C}$. The FRAP solution was freshly prepared before tests. Subsequently, $200 \mu \mathrm{L}$ of sample were mixed with $3 \mathrm{~mL}$ of the FRAP solution, incubated at $37^{\circ} \mathrm{C}$ for $30 \mathrm{~min}$, and the absorbance was measured at $593 \mathrm{~nm}$ in spectrophotometer (Varian Cary 50, Palo Alto, CA, USA). The FRAP values were expressed in $\mathrm{mM} \mathrm{Fe}^{2+}$ $\mathrm{L}^{-1}$, using a calibration curve of iron $\left(\mathrm{Fe}^{2+}\right)$ sulphate solution. Experiments were conducted in triplicate.

\subsubsection{Antioxidant activity by ABTS assay}

The cation radical discoloration test (ABTS) of the extracts or microencapsulated extracts, was determined as described by Ballesteros et al. (2015) with some modifications. The ABTS radical cation was prepared by mixing $7 \mathrm{mM}$ of 2,2'-azino-bis (3-ethylbenzthiazoline-6sulphonic) diammonium acid (ABTS) dissolved in distilled water with a $2.45 \mathrm{mM}$ potassium persulfate solution, mixed and left at $4{ }^{\circ} \mathrm{C}$ in the dark during 14-16 h, until to achieve a stable oxidative state. After this time, the ABTS radical cation solution was diluted in a solution of $20 \mathrm{mM}$ acetate buffer ( $\mathrm{pH} 4.5)$ to an absorbance of $0.70 \pm 0.01$ at $734 \mathrm{~nm}$. The assays were performed by mixing $10 \mu \mathrm{L}$ of sample with $200 \mu \mathrm{L}$ of ABTS radical cation solution. The mixture was maintained for $30 \mathrm{~min}$ in the dark at room temperature and then the absorbance was measured at $734 \mathrm{~nm}$. Ethanol was used as control. The percentage of inhibition of the ABTS radical cation was calculated using the same equation used for DPPH assay. All experiments were performed in triplicate.

\subsection{Characterization of microencapsulated extracts}

\subsubsection{Encapsulation efficiency}

Encapsulation efficiency (\%EE) was calculated according to the following equation:

$\mathrm{EE}(\%)=\frac{\mathrm{TPC}_{\text {total }}-\mathrm{TPC}_{\text {free }}}{\mathrm{TPC}_{\text {total }}} \times 100$

where $\mathrm{TPC}_{\text {total }}$ represents the total amount of initial total phenolic compounds present in the sample added during microcapsule production, and $\mathrm{TPC}_{\text {free }}$ the free total phenolic compounds detected in the microcapsule.

\subsubsection{Scanning electron microscopy (SEM) analysis}

The structure and size of the microcapsules was determined through scanning electron microscopy (SEM) technique, using a Phillips XL30 ESEM microscope (Eindhoven, Netherlands). In order to record the SEM micrographs, the microcapsules were placed on a stainless-steel holder, following by a drying at room temperature; then they were coated with a fine layer of gold $(40-50 \mathrm{~nm})$ and examined using an acceleration voltage of $5 \mathrm{kV}$.

\subsubsection{Thermal analysis}

Thermal transition properties of neat alginate and dried microcapsules $(20 \mathrm{mg})$ were analyzed using a Differential Scanning Calorimeter (DSC) with thermogravimetric analysis (TGA) in a simultaneous thermal analysis SDT Q600 analyzer V20.9 (New Castle, DE, USA). The thermograms were obtained at a scanning rate of $10{ }^{\circ} \mathrm{C}$ $\min ^{-1}$ in $30-900^{\circ} \mathrm{C}$ temperature range.

\subsubsection{Extracts release assays}

In order to simulate the passage and the delivery of the microencapsulated extracts through the GI tract the following assays were performed: for gastric conditions, $20 \mathrm{~g}$ of each sample were placed in a solution of $0.5 \% \mathrm{NaCl}$ in flasks, and the $\mathrm{pH}$ was adjusted to $1-3$ using $0.1 \mathrm{M} \mathrm{HCl}$. The mixture was incubated at $37^{\circ} \mathrm{C}$, under shaking at
$110 \mathrm{rpm}$ for $2 \mathrm{~h}$ (Gbassi and Vandamme, 2012). Then, the microencapsulated extracts were taken from the gastric juice model and filtered under vacuum through a membrane filter $(0.45 \mu \mathrm{m})$. Subsequently, they were placed in the intestinal juice model, a solution that consisted of $\mathrm{NaCl}\left(6.5 \mathrm{~g} \mathrm{~L}^{-1}\right), \mathrm{KCl}\left(0.8 \mathrm{~g} \mathrm{~L}^{-1}\right), \mathrm{CaCl}_{2}\left(0.2 \mathrm{~g} \mathrm{~L}^{-1}\right)$, and $\mathrm{NaHCO}_{3}\left(1.4 \mathrm{~g} \mathrm{~L}^{-1}\right)$ with a pH of $6.5-7.5$. The mixture was incubated under shaking at $110 \mathrm{rpm}$ at $37^{\circ} \mathrm{C}$ for $20 \mathrm{~h}$. The release of the extracts was measured by spectrophotometry at $2,4,6,8,10$, and $22 \mathrm{~h}$ at the wavelength of maximum absorption observed for these extracts previously determined (194 nm), using a Spectrophotometer (DR5000-03, Hach, USA) (Calero et al., 2008).

\subsection{Statistical analysis}

Statistical analysis was performed through analysis of variance (ANOVA) $(p<0.05)$, and the mean comparison test was conducted using the Tukey test $(p=0.05)$ with the software "R" V 3.2.0. Models were fitted to in vitro release data by non-linear regression, using the software STATISTICA $^{\mathrm{rm}}$ v7.0 (Statsoft Inc., USA).

\section{Results and discussion}

\subsection{TPC and antioxidant activity of extracts and microencapsulated extracts of Flourensia spp.}

The results showed that the concentration of polyphenols and the antioxidant activity of the microencapsulated extracts follow the same trend as the crude extracts (Tables 1 and 2). For TPC of the ethanol extracts of the species of Flourensia under study, the ANOVA showed statistical differences $(p<0.05)$, being higher for $F$. retinophylla, followed by $F$. microphylla, and $F$. cernua, with values of $63.5 \pm 2.0$, $46.9 \pm 1.7$, and $30.1 \pm 0.2 \mathrm{mg}$ GAE $100 \mathrm{mg}^{-1}$ extract, respectively (Table 1). Similarly, the highest content of phenolic compounds was observed for the microcapsules of $F$. retinophylla extract (Table 2). However, the stronger $(p<0.05)$ antioxidant activity was detected for both, the extract and microcapsules of $F$. microphylla, being this behavior presented with all the different methods used for antioxidant determination (DPPH, ABTS, and FRAP). It is noteworthy that this activity remained similar for the crude extract and in its encapsulated form; which may be associated to the presence of certain compounds (e.g. flavonols and caffeic acids) identified in the extract with elevated stability and potential antioxidant (Jasso de Rodríguez et al., 2017a).

The microencapsulated extracts presented a phenolic content nearly two orders lower than the crude extracts. This may be due to the presence of an interaction between the polymeric structure of alginate and the chemical compounds present in the extracts, which generates a protection of microcapsule to the extract (Li et al., 2007a,b).

\subsection{Encapsulation efficiency}

The encapsulation efficiency (\%EE) of microencapsulated extracts

Table 1

Total phenolic content (TPC) and antioxidant activities of ethanol extracts of Flourensia spp. leaves.

\begin{tabular}{lllll}
\hline Ethanol extract & $\begin{array}{l}\text { TPC } \\
(\mathrm{mg} \mathrm{GAE} \\
\end{array}$ & \multicolumn{3}{l}{ Antioxidant activity } \\
\cline { 3 - 5 } \cline { 3 - 5 } & & $\begin{array}{l}\text { DPPH } \\
(\%)\end{array}$ & $\begin{array}{l}\text { ABTS } \\
(\%)\end{array}$ & $\begin{array}{l}\text { FRAP } \\
\left(\mathrm{mM} \mathrm{Fe}^{2+}\right)\end{array}$ \\
\hline F. cernua & $30.1 \pm 0.2^{\mathrm{c}}$ & $43.3 \pm 1.6^{\mathrm{b}}$ & $32.5 \pm 1.3^{\mathrm{b}}$ & $1.2 \pm 0.2^{\mathrm{b}}$ \\
F. microphylla & $46.9 \pm 1.7^{\mathrm{b}}$ & $85.2 \pm 0.1^{\mathrm{a}}$ & $92.5 \pm 0.3^{\mathrm{a}}$ & $4.0 \pm 0.2^{\mathrm{a}}$ \\
F. retinophylla & $63.5 \pm 2.0^{\mathrm{a}}$ & $44.1 \pm 1.0^{\mathrm{b}}$ & $39.0 \pm 8.3^{\mathrm{b}}$ & $1.3 \pm 0.0^{\mathrm{b}}$ \\
\hline
\end{tabular}

Values in the same column followed by different letters are statistically different $(p<0.05)$.

Values reported are the mean \pm standard deviation. 
Table 2

Total phenolic content (TPC) and antioxidant activities of microencapsulated ethanol extracts of Flourensia spp.

\begin{tabular}{|c|c|c|c|c|}
\hline \multirow{2}{*}{$\begin{array}{l}\text { Microencapsulated } \\
\text { extracts }\end{array}$} & \multirow{2}{*}{$\begin{array}{l}\text { TPC } \\
(\mathrm{mg} \mathrm{GAE} \\
\left.100 \mathrm{mg}^{-1}\right)\end{array}$} & \multicolumn{3}{|c|}{ Antioxidant activity } \\
\hline & & $\begin{array}{l}\text { DPPH } \\
(\%)\end{array}$ & $\begin{array}{l}\text { ABTS } \\
(\%)\end{array}$ & $\begin{array}{l}\text { FRAP } \\
\left(\mathrm{mM} \mathrm{Fe} \mathrm{F}^{2+} \mathrm{L}^{-1}\right)\end{array}$ \\
\hline F. cernua & $0.5 \pm 0.0^{c}$ & $3.9 \pm 0.6^{c}$ & $12.2 \pm 1.3^{\mathrm{b}}$ & $0.6 \pm 0.0^{\mathrm{b}}$ \\
\hline F. microphylla & $0.7 \pm 0.0^{\mathrm{b}}$ & $84.4 \pm 0.2^{\mathrm{a}}$ & $50.2 \pm 1.2^{\mathrm{a}}$ & $1.8 \pm 0.1^{\mathrm{a}}$ \\
\hline F. retinophylla & $0.8 \pm 0.0^{\mathrm{a}}$ & $7.6 \pm 0.5^{b}$ & $12.3 \pm 1.1^{\mathrm{b}}$ & $0.5 \pm 0.0^{\mathrm{b}}$ \\
\hline
\end{tabular}

Values in the same column followed by different letters are statistically different $(p<0.05)$.

Values reported are the mean \pm standard deviation.

was in general elevated for all the species, with values of $99.3 \pm 0.0$, $99.7 \pm 0.0$, and $99.7 \pm 0.0 \%$ for F. cernua, F. microphylla, and F. retinophylla, respectively. da Rosa et al. (2014) suggested the dependency of the \%EE with the coating material used for the encapsulation, as they observed different \%EE values (about 46.5-75.5\%) when encapsulated phenolic compounds from blueberry in diverse matrixes ( $\beta$-cyclodextrin, chitosan, xanthan, and hydrogel). Also, the composition and type of core material influences the encapsulation efficiency, as it has been reported that molecules with elevated hydrophobicity and smaller size present higher affinity for the coating material (Fang and Bhandari, 2010). Hu et al. (2019) detected \%EE in the range of 14.4 to $27.9 \%$ depending on the citrus used as source of flavonoids, and associated this effect with the solubility of flavonoids in the encapsulating matrix (whey protein concentrate). Therefore, the high values obtained for the $\%$ EE proven the capacity of alginate to load the compounds present in the extracts of Flourensia species under study, as well as the interaction between the components; which could be performed through hydrogen bonding (Sanna et al., 2015).

\subsection{Microscopy observations of microencapsulated extracts}

The morphology and the size were determined by SEM, which showed capsules mostly spherical-shape (Fig. 1). The size distribution showed dimensions ranging from 2.1 to $3.2 \mu \mathrm{m}$ for capsules of $F$. cernua and $F$. retinophylla, respectively; whereas the capsules of $F$. microphylla presented a greater variability in shape and size, with dimensions between 4.5 to $68.8 \mu \mathrm{m}$. In general, the values obtained allowed to classify the capsules formed as microcapsules, as they are in the range for this category $(1.0-5000 \mu \mathrm{m})$ (Hu et al., 2019). The larger size of $F$. microphylla capsules may be related to having maintained a large part of their antioxidant activity (Table 2), probably due to a greater interaction between the bioactive compounds of the extract and the polymeric structure of the alginate. The results are comparable with those reported by Likitdecharoj and Ratanavaraporn (2018) for green tea encapsulated in gelatin, which had diameters between 66 and $73 \mu \mathrm{m}$; and Sanna et al. (2015) for resveratrol microencapsulated in a polymeric matrix of chitosan poly(D,L-lactic-co-glycolic acid) with values from 11 to $20 \mu \mathrm{m}$.

\subsection{Thermal analysis}

The presence of the extracts into alginate microcapsules is demonstrated by the thermal analysis of the samples. Fig. 2 shows the thermogravimetric and DSC analysis of the alginate microcapsules with and without Flourensia extracts. The DSC scans of neat alginate capsules (Fig. 2a) showed the characteristics peaks previously reported: one endothermic peak at $70^{\circ} \mathrm{C}$ corresponding to the hydration water; two exothermic peaks at $180^{\circ} \mathrm{C}$ and $280^{\circ} \mathrm{C}$, and another endothermic signal at $200{ }^{\circ} \mathrm{C}$ (Deng et al., 2019; Anbinder et al., 2011). Also, it is observed three exothermic peaks at $280^{\circ} \mathrm{C}, 425^{\circ} \mathrm{C}$, and $600^{\circ} \mathrm{C}$ in the thermogram of alginate capsules. As Anbinder et al. (2011) explained, the shift of
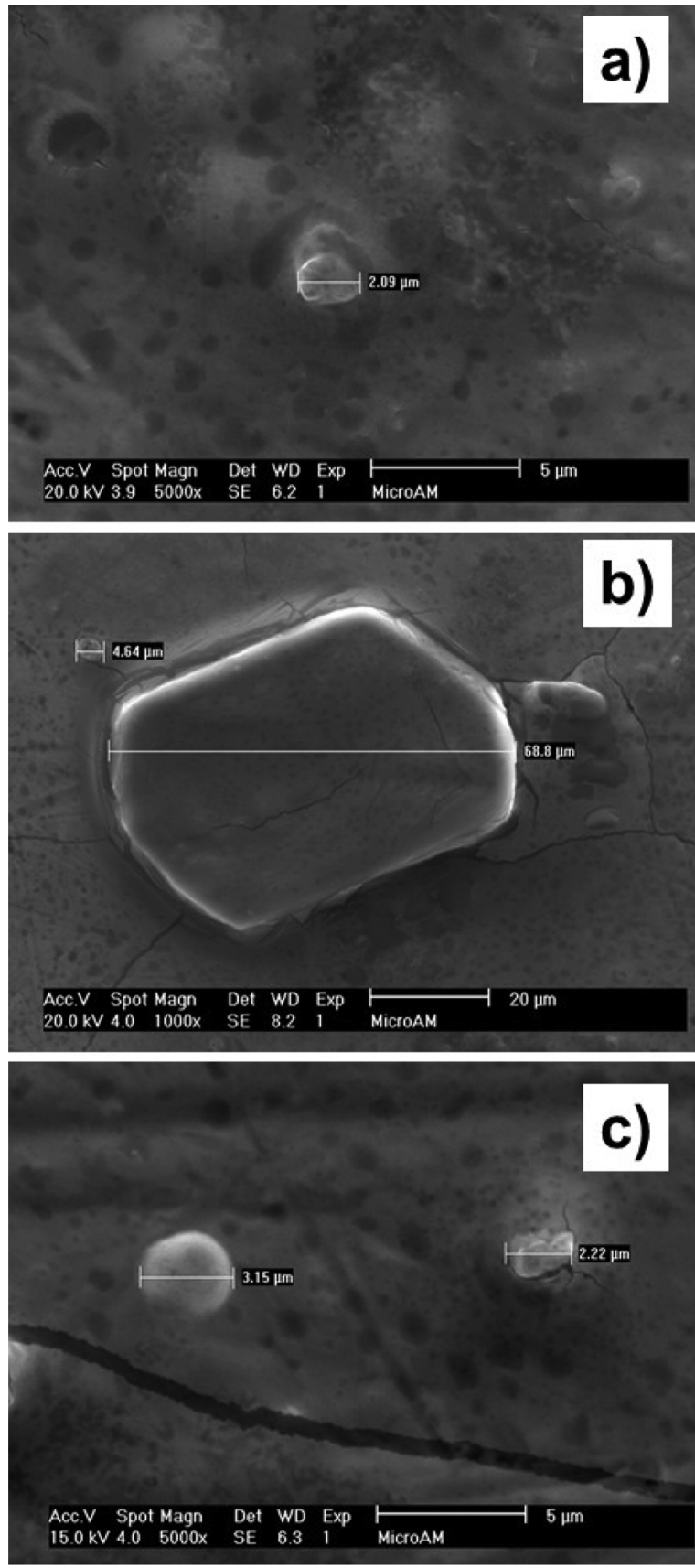

Fig. 1. SEM images of microcapsules of Flourensia spp. extracts: a) F. cernua, b) F. microphylla, and c) F. retinophylla.

endothermic peak at $180^{\circ} \mathrm{C}-190^{\circ} \mathrm{C}$ observed in microcapsules with extract, would be evidence of the presence of extract into the encapsulates, guaranteed the interaction between the polyphenols of the extract and the polymeric structure of alginate. On the other hand, the microencapsulated extracts exhibited a considerable increase in the intensity of the exothermic peak centered at $600^{\circ} \mathrm{C}$, which was more marked for microcapsules of F. microphylla (Fig. 2a). This may corroborate the presence of specific compounds of the Flourensia extracts within the capsules, which vary according the source of extract. The protection of polymeric capsule for each extract and encapsulation were also confirmed, as microcapsules of Flourensia extracts presented lower mass loss when compared with that of neat alginate capsules (Fig. 2b) (da Rosa et al., 2014). This effect was more evident for the microcapsules of $F$. microphylla (Fig. 2b), agrees with the stronger intensity at $\sim 550^{\circ} \mathrm{C}$ observed in the DSC extracts (Fig. 2a). This corresponds with 

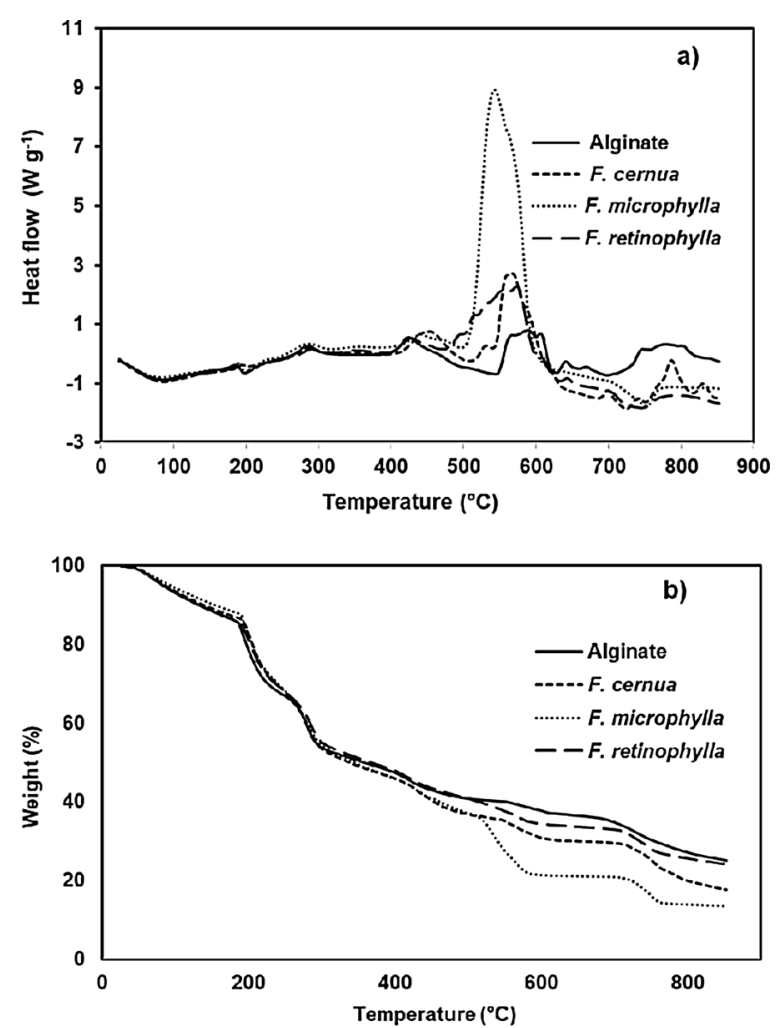

Fig. 2. a) Differential thermal analysis, and b) Thermogravimetric analysis of microcapsules of neat alginate, and extracts of $F$. cernua, F. microphylla, and $F$. retinophylla.

the higher antioxidant activity determined for the microcapsules of $F$. microphylla (Table 2), as well as with their larger size observed (Fig. 1b).

\subsection{Microencapsulated extract release in simulated gastrointestinal fluids}

The extract released (\%) from the microcapsules in gastric fluids is presented in Fig. 3. During the test (2 h, pH 1.2), it was observed an extract release from the dry microcapsules of $26.5 \%$ to $53.3 \%$, while for fresh microcapsules it was in the range of $7.7 \%$ to $14.5 \%$. In the first instance, these data are not encouraging as it is desirable that the release in the stomach of an active ingredient is less than $10 \%$. This is because for a drug to be effective, it must be absorbed in the intestinal

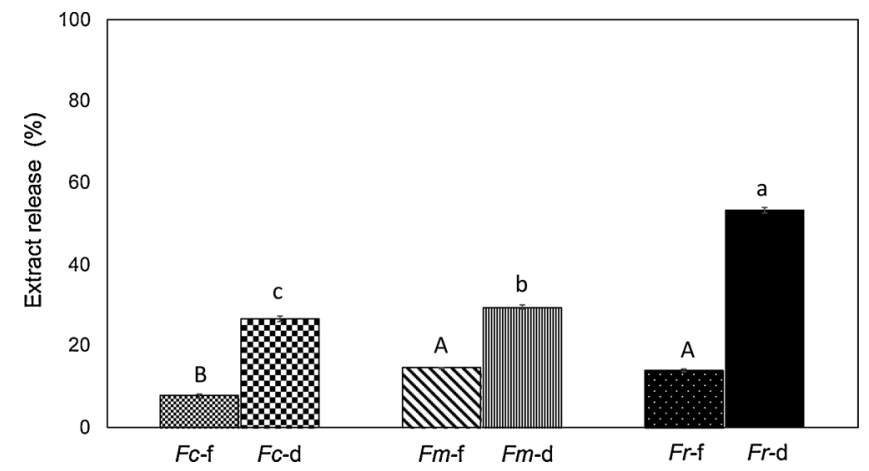

Fig. 3. Extract release in gastric fluids $(\mathrm{pH} 1.2)$ from fresh (-f) and dried (-d) microcapsules of $F$. cernua $(F c), F$. microphylla $(F m)$, and $F$. retinophylla $(F r)$. Values are the mean and the error bars show the standard deviation. Uppercase letters are used to compare means of fresh microcapsules; lowercase letters are used to compare means of dried microcapsules.

Means with the same uppercase and lowercase letter did not differ by Tukey's test $(p<0.05)$ treatment, so the ideal is that the release is as much as possible in the intestine and not in the stomach. However, there are reports of release of natural extracts from other matrices that are even superior to those obtained in this work. Gorbunova et al. (2018) reported a high release (between $29 \%$ and $36 \%$ ) of betacyanins, betaxanthins, and phenolic compounds from encapsulated extracts of alginate in gastric medium (pH 1.2). Likewise, Moreno et al. (2018) also reported a release higher than $20 \%$ of grape encapsulated by spray-dry. In this sense, it is interesting to carry out further studies in which some type of coating of the encapsulates is used to allow the release at the desired site (Colilla et al., 2010). Anbinder et al. (2011) demonstrated that the chitosan coating of alginate capsules prevents the release of polyphenols compounds from yerba mate extracts in gastric fluids, promoting the release in intestinal fluids. Also, it seems to be that the microcapsules of alginate enhance the solubility of the extracts of Flourensia species in aqueous solutions, and when dispersed it has a greater contact area with the fluid, increasing the percentage of release of the extract in the dry capsules (Zheng et al., 2011).

Regarding the release of Flourensia extracts from fresh microcapsules in intestinal fluid ( $\mathrm{pH} 7$ ), the values reached up to $30 \%$ at $22 \mathrm{~h}$; whereas for dried microcapsules the release was significantly greater: $58 \%, 64 \%$, and $80 \%$ for F. cernua, F. microphylla, and F. retinophylla, respectively (Fig. 4). In addition, it can be remarked that the release is constant throughout the time interval studied, which may be related to a prolonged and gradual release effect. It has been reported that for some materials the release of anti-inflammatory drugs, such as zoleodrante, is considered slow, as after $4 \mathrm{~d}$ a release of only $45 \%$ is achieved (Vallet-Regí et al., 2004).

It can be observed that the dried microcapsules of $F$. retinophylla presented the best behavior in the release of the extract (Fig. 4). However, it is necessary to consider that the release in gastric fluids was elevated (up 53\%); thus, only about $25 \%$ is released in intestinal fluids. While the dried microcapsules of $F$. microphylla released up to $38 \%$ of the extract in intestinal fluid. In this sense, it is clear that the encapsulation protects the extract allowing its controlled release in the intestinal fluids.

On the other hand, to determine the reaction order of the release kinetics, the calculations of the release rate constants of the encapsulated extracts were performed (Table 3 ). This approach is important as it could predict the release behavior of an extract or active compound, and it helps to develop strategies to improve the release (Safdar et al., 2019). Except for F. microphylla fresh microcapsules (Fmf), all the encapsulated extracts were fitted with zero-order model $\left(K_{o}\right)$,

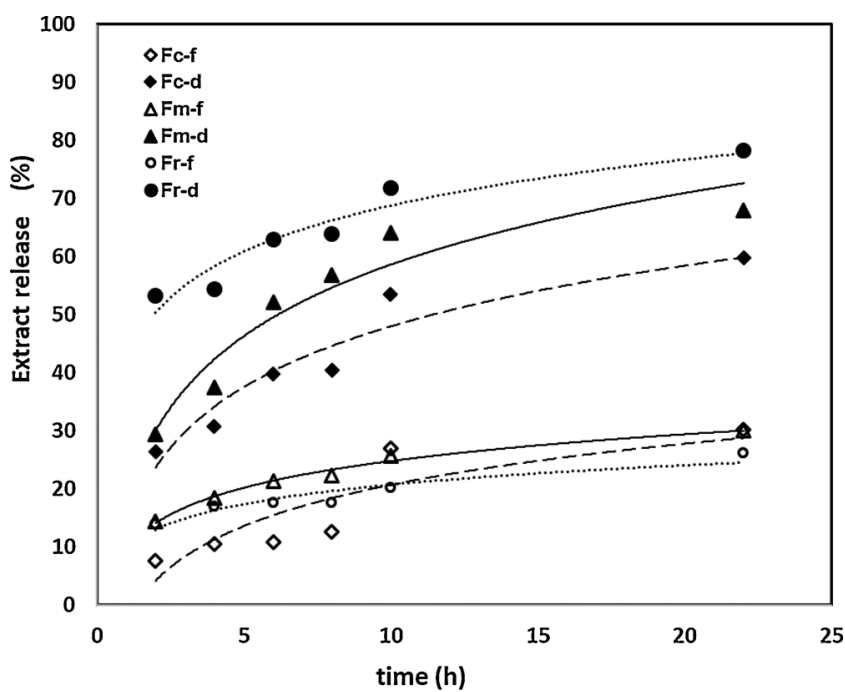

Fig. 4. Extract release in intestinal fluids $(\mathrm{pH} 7)$ from fresh (-f) and dried (-d) microcapsules of $F$. cernua $(F c), F$. microphylla $(F m)$, and $F$. retinophylla $(F r)$. 
Table 3

Kinetic parameters of extract release of Flourensia spp.

\begin{tabular}{|c|c|c|c|c|c|c|}
\hline \multirow[t]{2}{*}{ Sample } & \multicolumn{2}{|c|}{ Zero order } & \multicolumn{2}{|c|}{ First order } & \multicolumn{2}{|l|}{ Higuchi } \\
\hline & $K_{o}\left(\mathrm{~h}^{-1}\right)$ & $r^{2}$ & $K_{1}\left(h^{-1}\right)$ & $r^{2}$ & $K_{H}\left(\mathrm{~h}^{1 / 2}\right)$ & $r^{2}$ \\
\hline$F c-\mathrm{f}$ & 1.13 & 0.94 & 0.06 & 0.91 & 7.04 & 0.94 \\
\hline$F m-f$ & 0.70 & 0.75 & 0.03 & 0.66 & 4.61 & 0.98 \\
\hline$F r-\mathrm{f}$ & 0.57 & 0.95 & 0.03 & 0.89 & 3.63 & 0.96 \\
\hline$F c-d$ & 1.58 & 0.92 & 0.04 & 0.84 & 10.27 & 0.98 \\
\hline$F m-d$ & 1.68 & 0.97 & 0.03 & 0.94 & 11.50 & 0.86 \\
\hline$F r-d$ & 1.23 & 0.99 & 0.02 & 0.98 & 7.96 & 0.97 \\
\hline
\end{tabular}

Fc: F. cernua; Fm: F. microphylla; Fr: F. retinophylla; -f: fresh microcapsules; -d: dried microcapsules.

as a correlation adjustment greater than 0.9 was obtained. Otherwise, for the model of first-order $\left(K_{1}\right)$ were found correlations less than 0.9. This means that the release rate of the Flourensia spp. extracts encapsulated in alginate is constant and independent of the concentration (Safdar et al., 2019). The results obtained agree with those reported by Li et al. (2007a,b), who found that the release of garlic extracts, microencapsulated in ethyl cellulose/cellulose acetate phthalate, follows a zero-order kinetics between 60 and $120 \mathrm{~min}$. Another kinetic model reported to understand the active compounds release was proposed by Higuchi (1963), which describes an empirical process to drug release, and it is based-on Fick Law. Higuchi model $\left(K_{H}\right)$ considers that the release of a drug depends on time, thus, it is possible that an active principle is released following a zero-order model at the beginning of the ingestion and later change to a different behavior (Safdar et al., 2019). Then, from Table 3 it can be seen that the microcapsules of the extracts of $F$. cernua and $F$. retinophylla (fresh and dried) followed a zero-order model, and that a Higuchi model is also adjusted. The behavior of $F$. microphylla is different, as the release of the extract from fresh microcapsules is better fitted to the Higuchi model, while the release from the dry capsules follows a zero-order model. This may be associated to the larger particle size observed in the microcapsules (Fig. 1b), and also to the stronger antioxidant activity of this extract (Table 2).

The results obtained are promising, and suggest the effective protection that the microcapsule of alginate provides to the extracts of Flourensia species here studied.

\section{Conclusions}

Microcapsules of three species of Flourensia spp. were obtained by gelation with alginate, using a simple and reproducible methodology. The formation of capsules was demonstrated by the presence of an exothermic peak about $600^{\circ} \mathrm{C}$; while, their microscale size was confirmed by SEM, being in the range of $2.1-68.8 \mu \mathrm{m}$. The size dimension varied according to the source of extract. Most of the microcapsules presented a spherical shape, except for those of $F$. microphylla; however, they showed the most outstanding behavior, showing a strong antioxidant activity, even in its encapsulated form. In addition, the microcapsules of $F$. mycrophilla displayed the best release, as about $35 \%$ of extract can be profited, following a Higuchi model.

In general, it was proved the protection effect that the microcapsule provides to the extracts, obtaining better results of release in the intestinal fluids with the dry microcapsules than for the fresh microcapsules. Thus, this is a good vehicle of protection and delivery of functional compounds present in the Flourensia spp. This is the first scientific report of microencapsulation of Flourensia species, and their controlled release under in vitro GI digestion.

\section{Acknowledgements}

Author G.N. Puente Romero thanks Mexican Science and
Technology Council (CONACYT, Mexico) for MSc fellowship support. Authors would like to thank to María Guadalupe Moreno Esquivel, Edith E. Chaires Colunga, Olga L. Solís Hernández, and M. Leticia Rodríguez González of the Phytochemistry Laboratory from Universidad Autónoma Agraria Antonio Narro, for their support in the lab experiments.

\section{References}

Anbinder, P.S., Deladino, L., Navarro, A.S., Amalvy, J.I., Martino, M.N., 2011. Yerba mate extract encapsulation with alginate and chitosan systems: interactions between active compound encapsulation polymers. J. Encapsulation Adsorpt. Sci. 01, 80-87. https:// doi.org/10.4236/jeas.2011.14011.

Ballesteros, L.F., Cerqueira, M.A., Teixeira, J.A., Mussatto, S.I., 2015. Characterization of polysaccharides extracted from spent coffee grounds by alkali pretreatment. Carbohyd. Polym. 127, 347-354. https://doi.org/10.1016/j.carbpol.2015.03.047.

Benzie, I.F.F., Strain, J.J., 1996. The ferric reducing ability of plasma (FRAP) as a measure of “'antioxidant power"': the FRAP assay. Anal. Biochem. 239, 70-76. https://doi. org/10.1006/abio.1996.0292.

Calero, J., Sánchez, Y.F., Tórrez, R., Hernann, E., López, K., 2008. Elaboración y caracterización de microcápsulas gastrorresistentes de diclofenac obtenidas por gelificación iónica. Universitas (León) 2, 27-30.. http://revista.unanleon.edu.ni/ index.php/universitas/article/view/12/10.

Castillo, F., Hernández, D., Gallegos, G., Mendez, M., Rodríguez, R., Reyes, A., Aguilar, C.N., 2010. In vitro antifungal activity of plant extracts obtained with alternative organic solvents against Rhizoctonia solani Kühn. Ind. Crops Prod. 32, 324-328. https://doi.org/10.1016/j.indcrop.2010.05.013.

Cerqueira, M.A., Pinheiro, A.C., Silva, H.D., Ramos, P.E., Azevedo, M.A., Flores-López, M.L., Rivera, M.C., Bourbon, A.I., Ramos, Ó.L., Vicente, A.A., 2014. Design of bionanosystems for oral delivery of functional compounds. Food Eng. Rev. 6, 1-19. https://doi.org/10.1007/s12393-013-9074-3.

Cilek, B., Luca, A., Hasirci, V., Sahin, S., Sumnu, G., 2012. Microencapsulation of phenolic compounds extracted from sour cherry pomace: effect of formulation, ultrasonication time and core to coating ratio. Eur. Food Res. Technol. 235, 587-596. https://doi. org /10.1007/s00217-012-1786-8.

Colilla, M., Manzano, M., Izquierdo-Barba, I., Vallet-Reg, M., Boissiére, C., Sanchez, C., 2010. Advanced drug delivery vectors with tailored surface properties made of mesoporous binary oxides submicronic spheres. Chem. Mater. 22, 1821-1830. https:// doi.org/10.1021/cm9033484.

da Rosa, C.G., Borges, C.D., Zambiazi, R.C., Rutz, J.K., da Luz, S.R., Krumreich, F.D., Benvenutti, E.V., Nunes, M.R., 2014. Encapsulation of the phenolic compounds of the blackberry (Rubus fruticosus). LWT - Food Sci. Technol. 58, 527-533. https://doi.org/ 10.1016/j.lwt.2014.03.042.

Deng, Z., Wang, F., Zhou, B., Li, J., Li, B., Liang, H., 2019. Immobilization of pectinases into calcium alginate microspheres for fruit juice application. Food Hydrocoll. 89, 691-699. https://doi.org/10.1016/j.foodhyd.2018.11.031.

Desai, K.G.H., Park, H.J., 2005. Recent developments in microencapsulation of food ingredients. Dry.. Technol. Int. J. https://doi.org/10.1081/DRT-200063478.

Dillon, M.O., 1984. Taxonomy of the genus Flourensia (Asteraceae). Fieldiana n. ser. 16. pp. 1-66.

Dillon, M.O., Marby, T.J., 1977. Flavonoids aglycones from Flourensia. Phytochemistry $16,1318-1319$.

Fabra, M.J., Flores-López, M.L., Cerqueira, M.A., Jasso de Rodríguez, D., Lagaron, J.M., Vicente, A.A., 2016. Layer-by-layer technique to developing functional nanolaminate films with antifungal activity. Food Bioprocess Technol. 9, 471-480. https://doi.org/ 10.1007/s11947-015-1646-1.

Fang, Z., Bhandari, B., 2010. Encapsulation of polyphenols - a review. Trends Food Sci. Technol. 21, 510-523. https://doi.org/10.1016/j.tifs.2010.08.003.

Gbassi, G.K., Vandamme, T., 2012. Probiotic encapsulation technology: from microencapsulation to release into the gut. Pharmaceutics 4 (1), 149-163. https://doi.org/ 10.3390/pharmaceutics4010149.

Gorbunova, N., Bannikova, A., Evteev, A., Evdokimov, I., Kasapis, S., 2018. Alginatebased encapsulation of extracts from beta Vulgaris cv. Beet greens: stability and controlled release under simulated gastrointestinal conditions. LWT 93, 442-449. https://doi.org/10.1016/j.lwt.2018.03.075.

Gupta, S., Khan, S., Muzafar, M., Kushwaha, M., Yadav, A.K., Gupta, A.P., 2016. Encapsulation entrapping essential oil/flavors/aromas in food. In: In: Grumezescu, A.M. (Ed.), Encapsulations. Nanotechnology in the Agri-Food Industry Volume 2. Elsevier, pp. 229-268. https://doi.org/10.1016/B978-0-12-804307-3.00006-5.

Higuchi, T., 1963. Mechanism of sustained-action medication. Theoretical analysis of rate of release of solid drugs dispersed in solid matrices. J. Pharm. Sci. 52, 1145-1149. https://doi.org/10.1002/jps.2600521210.

Hu, Y., Kou, G., Chen, Q., Li, Y., Zhou, Z., 2019. Protection and delivery of mandarin (Citrus reticulata Blanco) peel extracts by encapsulation of whey protein concentrate nanoparticles. LWT 99, 24-33. https://doi.org/10.1016/j.lwt.2018.09.044.

Jafari, S.M., McClements, D.J., 2017. Nanotechnology approaches for increasing nutrient bioavailability. Advances in Food and Nutrition Research, 1st ed. Elsevier Inc.https:// doi.org/10.1016/bs.afnr.2016.12.008.

Jasso de Rodríguez, D., Carrillo-Lomelí, D.A., Rocha-Guzmán, N.E., Moreno-Jiménez, M.R., Rodríguez-García, R., Díaz-Jiménez, M.L.V., Flores-López, M.L., VillarrealQuintanilla, J.A., 2017a. Antioxidant, anti-inflammatory and apoptotic effects of Flourensia microphylla on HT-29 colon cancer cells. Ind. Crops Prod. 107, 472-481. https://doi.org/10.1016/j.indcrop.2017.03.034. 
Jasso de Rodríguez, D., Hernández-Castillo, D., Angulo-Sánchez, J.L., Rodríguez-García, R., Villarreal Quintanilla, J.A., Lira-Saldivar, R.H., 2007. Antifungal activity in vitro of Flourensia spp. extracts on Alternaria sp., Rhizoctonia solani, and Fusarium oxysporum. Ind. Crops Prod. 25, 111-116. https://doi.org/10.1016/j.indcrop.2006.08. 007.

Jasso de Rodríguez, D., Salas-Méndez, E. de J., Rodríguez-García, R., Hernández-Castillo, F.D., Díaz-Jiménez, M.L.V., Sáenz-Galindo, A., González-Morales, S., Flores-López, M.L., Villarreal-Quintanilla, J.A., Peña-Ramos, F.M., Carrillo-Lomelí, D.A., 2017b. Antifungal activity in vitro of ethanol and aqueous extracts of leaves and branches of Flourensia spp. against postharvest fungi. Ind. Crops Prod. 107, 499-508. https://doi. org/10.1016/j.indcrop.2017.04.054.

Li, H. Bin, Cheng, K.W., Wong, C.C., Fan, K.W., Chen, F., Jiang, Y., 2007a. Evaluation of antioxidant capacity and total phenolic content of different fractions of selected microalgae. Food Chem. 102, 771-776. https://doi.org/10.1016/j.foodchem.2006. 06.022.

Li, Y., Xu, S.-Y., Sun, D.-W., 2007b. Preparation of garlic powder with high allicin content by using combined microwave-vacuum and vacuum drying as well as microencapsulation. J. Food Eng. 83, 76-83. https://doi.org/10.1016/j.jfoodeng.2007.02. 057.

Likitdecharoj, P., Ratanavaraporn, J., 2018. Comparative study in physico-chemical properties of gelatin derivatives and their microspheres as carriers for controlled release of green tea's extract. J. Drug Deliv. Sci. Technol. 47, 367-374. https://doi. org $/ 10.1016 /$ j.jddst.2018.08.005.

McClements, D.J., Xiao, H., 2017. Designing food structure and composition to enhance nutraceutical bioactivity to support cancer inhibition. Semin. Cancer Biol. 46, 215-226. https://doi.org/10.1016/j.semcancer.2017.06.003.

Mendez, M., Rodríguez, R., Ruiz, J., Morales-Adame, D., Castillo, F., Hernández-Castillo, F.D., Aguilar, C.N., 2012. Antibacterial activity of plant extracts obtained with alternative organics solvents against food-borne pathogen bacteria. Ind. Crops Prod. 37, 445-450. https://doi.org/10.1016/j.indcrop.2011.07.017.

Molina-Salinas, G.M., Ramos-Guerra, M.C., Vargas-Villarreal, J., Mata-Cárdenas, B.D., Becerril-Montes, P., Said-Fernández, S., 2006. Bactericidal activity of organic extracts from Flourensia cernua DC against strains of Mycobacterium tuberculosis. Arch. Med. Res. 37, 45-49. https://doi.org/10.1016/j.arcmed.2005.04.010.

Moreno, T., Cocero, M.J., Rodríguez-Rojo, S., 2018. Storage stability and simulated gastrointestinal release of spray dried grape marc phenolics. Food Bioprod. Process. 112, 96-107. https://doi.org/10.1016/j.fbp.2018.08.011.
Munin, A., Edwards-Lévy, F., 2011. Encapsulation of natural polyphenolic compounds; a review. Pharmaceutics 3 (4), 793-829. https://doi.org/10.3390/ pharmaceutics 3040793.

Pinheiro, A.C., Gonçalves, R.F., Madalena, D.A., Vicente, A.A., 2017. Towards the understanding of the behavior of bio-based nanostructures during in vitro digestion. Curr. Opin. Food Sci. 15, 79-86. https://doi.org/10.1016/j.cofs.2017.06.005.

Rios, M.Y., 2015. Chemistry and biology of the genus Flourensia (Asteraceae). Chem. Biodivers. 12 (11), 1595-1634. https://doi.org/10.1002/cbdv.201400220.

Safdar, R., Omar, A.A., Arunagiri, A., Reguphati, I., Thanabalan, M., 2019. Potential of chitosan and its derivatives for controlled drug release applications - A review. J. Drug Deliv. Sci. Technol. 49, 642-659. https://doi.org/10.1016/j.jddst.2018.10.020.

Salazar, R., Pozos, M.E., Cordero, P., Perez, J., Salinas, M.C., Waksman, N., 2008. Determination of the antioxidant activity of plants from northeast Mexico. Pharm. Biol. 46, 166-170. https://doi.org/10.1080/13880200701498952.

Sanna, V., Roggio, A.M., Pala, N., Marceddu, S., Lubinu, G., Mariani, A., Sechi, M., 2015. Effect of chitosan concentration on PLGA microcapsules for controlled release and stability of resveratrol. Int. J. Biol. Macromol. 72, 531-536. https://doi.org/10.1016/ j.ijbiomac.2014.08.053.

Singleton, V.L., Orthofer, R., Lamuela-Raventós, R.M., 1999. Analysis of total phenols and other oxidation substrates and antioxidants by means of folin-ciocalteu reagent. Method. Enzymol. 299, 152-178. https://doi.org/10.1016/S0076-6879(99)99017-1. Stuppner, H., Müller, E.P., 1994. Rare flavonoid aglycones from Flourensia retinophylla. Phytochemistry 37, 1185-1187. https://doi.org/10.1016/S0031-9422(00)89554-0.

Téllez, M., Estell, R., Fredrickson, E., Powell, J., Wedge, D., Schrader, K., Kobaisy, M., 2001. Extracts of Flourensia cernua(L): Volatile constituents and antifungal, antialgal, and antitermite bioactivities. J. Chem. Ecol. 27, 2263-2273. https://doi.org/10. 1023/A:1012283005014.

Vallet-Regí, M., Doadrio, J.C., Doadrio, A.L., Izquierdo-Barba, I., Pérez-Pariente, J., 2004. Hexagonal ordered mesoporous material as a matrix for the controlled release of amoxicillin. Solid State Ion. 172, 435-439. https://doi.org/10.1016/j.ssi.2004.04. 036.

Vines, R.A., 1960. Trees, Shrubs and Woody Vines of the Southwest. University of Texas at Austin.

Zheng, L., Ding, Z., Zhang, M., Sun, J., 2011. Microencapsulation of bayberry polyphenols by ethyl cellulose: preparation and characterization. J. Food Eng. 104, 89-95. https://doi.org/10.1016/j.jfoodeng.2010.11.031. 